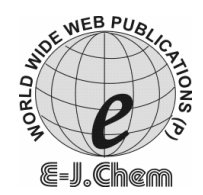

http://www.e-journals.net
ISSN: 0973-4945; CODEN ECJHAO

E-Journal of Chemistry 2009, 6(2), 303-307

\title{
2-Hydroxy-4-n-propoxy-5-bromoacetophenone oxime as an Analytical Reagent for Gravimetric Determination of $\mathrm{V}(\mathrm{V})$
}

\author{
AMBILY P NAIR* and J. CHRISTINE \\ *Department of Chemistry, \\ Amity School of Engineering and Technology, \\ Amity University, Sector-125, Noida-201303, India. \\ apnair@ase.amity.edu
}

Received 1 August 2008; Accepted 1 October 2008

\begin{abstract}
Hydroxy-4-n-propoxy-5-bromoacetophenone oxime (HnPBAO) was developed as a new analytical reagent for the gravimetric determination of pentavalent vanadium ion. In the $\mathrm{pH}$ range 4.0-6.0, the reagent gave a brown coloured precipitate with $\mathrm{V}(\mathrm{V})$. Job's method and Mole ratio method revealed that the stoichiometry of the complex is 1:1 (metal: ligand). Beer's law is obeyed up to $20.38 \mathrm{ppm}$ of $\mathrm{V}(\mathrm{V})$. Molar absorptivity and Sandells sensitivity at $450 \mathrm{~nm}$ were found to be $10.22 \times 10^{2} \mathrm{~L} / \mathrm{mol} / \mathrm{cm}$ and $0.049 \mu \mathrm{g} / \mathrm{cm}^{2}$ respectively. The stability constant of V(V)-HnPBAO complex is found to be $1.195 \times 10^{6}$. Gibb's free energy change for complex formation reaction was found to be -8.34 $\mathrm{kcal} / \mathrm{mol}$. The reagent can be used for the analysis of vanadium in ferrovanadium alloys.
\end{abstract}

Keywords: Oxime, Analytical reagent, 2-Hydroxy-4-n-propoxy-5-bromoacetophenone

\section{Introduction}

A wide variety of reagents are available for the study of metal ions in analytical chemistry. They include thiosemicarbazones ${ }^{1,2}$, oximes ${ }^{3,4}, o$-hydroxy ketoximes ${ }^{5}$ etc. These reagents are generally used for the determination of transition metal ions using gravimetric and spectrophotometric techniques. In the present work, the use of 2-Hydroxy-4-n-propoxy-5bromoacetophenone oxime (HnPBAO) as a gravimetric reagent for $\mathrm{V}(\mathrm{V})$ has been reported. Spectrophotometric methods have been used to confirm the stoichiometry of the complex and to determine the stability constants of the complex. The reagent was used to determine vanadium in alloys. 


\section{Experimental}

Schimadzu UV-Visible spectrophometer (160A) was used for all absorbance measurements and $\mathrm{pH}$ of the solutions was measured on Equiptronics (EQ-614) and buffer solutions of required $\mathrm{pH}$ were obtained using acetic acid-sodium acetate solution of suitable concentrations.

\section{Synthesis of 2-hydroxy-4-n-propoxy-5-bromoacetophenone oxime (HnPBAO)}

Resacetophenone was prepared using resorcinol, acetic acid and anhydrous $\mathrm{ZnCl}_{2}$. This was treated with bromine in acetic acid and poured on ice cold water. The product was crystallized from ethanol. 2,4-Dihydroxy-5-bromoacetophenone obtained was mixed with anhydrous potassium carbonate, $n$-propyliodide in acetone and refluxed. Hydroxylamine hydrochloride and sodium acetate were added and solution was again refluxed on a water bath. The mixture was poured on ice and light green solid got precipitated which was crystallized from ethanol (m.p $172 \pm 1{ }^{\circ} \mathrm{C}$ ). The reagent was soluble in solvents like ethanol, DMF etc.

The elemental analysis of the reagent showed the percentage of carbon, hydrogen and nitrogen as $45.83,4.83$ and $4.86 \%$ respectively. (The calculated value was found to be $46.12,4.72$ and $4.68 \%$ for carbon, hydrogen and nitrogen respectively).

\section{Stock solution}

Ammonium metavanadate $(0.05 \mathrm{M})$ solution was prepared by dissolving the requisite amount (1.426 g) of salt in double distilled water, little free acid was added and standardized titrimetrically. Solutions of required concentrations were prepared by diluting the above stock solution. Solution of the reagent $\mathrm{HnPBAO}(0.05 \mathrm{M})$ was prepared by dissolving oxime in pure ethanol.

\section{Gravimetric procedure}

A $0.05 \mathrm{M}$ solution of the reagent in pure ethanol was used. Ammonium metavanadate solution $(0.05 \mathrm{M}, 10 \mathrm{~mL})$ taken in a clean beaker was diluted to about $100 \mathrm{~mL}$ with distilled water and $\mathrm{pH}$ of the solution was adjusted between 3.0 to 4.0 using sodium acetate-acetic acid buffer. The solution was warmed to $60^{\circ} \mathrm{C}$ and a small excess of reagent $(0.05 \mathrm{M}, 22$ $\mathrm{mL}$ ) was added. The light brown precipitate obtained was digested on water bath for $60 \mathrm{~min}$ at $60-70{ }^{\circ} \mathrm{C}$. The precipitate was filtered through a previously weighed sintered glass crucible (G4) and washed with warm water followed by ethanol to remove excess of the reagent which might have precipitated on dilution. The chelate was dried to constant weight at $110-115^{\circ} \mathrm{C}$ in hot air oven, cooled and weighed.

\section{Gravimetric determination of $V(V)$}

To establish the applicability of the reagent for gravimetric estimation of $\mathrm{V}(\mathrm{V})$, the metal ion was determined in the $\mathrm{pH}$ range 4.0 to 6.0 . The maximum error being $\pm 1.5 \%$. Estimations were done at $\mathrm{pH} 5.0$ using different aliquots of $\mathrm{V}(\mathrm{V})$. In all cases the error in $\mathrm{V}(\mathrm{V})$ content did not exceed $\pm 0.46 \%$ (Table 1 ).

Table 1. Result of gravimetric estimation of $\mathrm{V}(\mathrm{V})$ at $\mathrm{pH} 5.0, \mathrm{~V}(\mathrm{~V})-\mathrm{HnPBAO}$

\begin{tabular}{ccccc}
\hline Weight of $\mathrm{V}(\mathrm{V})$ & Weight of $\mathrm{V}(\mathrm{V})$ & \multicolumn{2}{c}{ Weight of $\mathrm{V}(\mathrm{V})$} & \multicolumn{2}{c}{ Relative Error } \\
\cline { 4 - 5 } taken in mg & complex in mg & ion found in mg & mg & $\%$ \\
\hline 25.47 & 169.85 & 25.57 & +0.10 & +0.39 \\
38.20 & 254.86 & 38.38 & +0.18 & +0.46 \\
50.94 & 339.78 & 51.17 & +0.23 & +0.44 \\
\hline
\end{tabular}




\section{Interferences}

To study the effect of foreign ions on gravimetric determination of $\mathrm{V}(\mathrm{V}), 8-10 \mathrm{mg}$ of various cations were added to a solution containing $25.47 \mathrm{mg}$ of $\mathrm{V}(\mathrm{V})$ at $\mathrm{pH} 5.0$ and gravimetric estimations were done. It was observed that $\mathrm{Ca}(\mathrm{II}), \mathrm{Mg}(\mathrm{II}), \mathrm{Ni}(\mathrm{II}), \mathrm{Sr}(\mathrm{II}), \mathrm{Cd}(\mathrm{II})$, $\mathrm{Ba}(\mathrm{II}), \mathrm{K}(\mathrm{I})$ and $\mathrm{Na}(\mathrm{I})$ do not interfere at this $\mathrm{pH}$ but $\mathrm{Cu}(\mathrm{II}), \mathrm{Fe}(\mathrm{III})$ and $\mathrm{Co}(\mathrm{II})$ interfered seriously. Many common anions like chlorides, bromides, iodides, nitrates, nitrites and sulphates were not found to interfere.

Spectrophotometric study of $V(V)-H n P B A O$ complex

For taking the absorbance spectra, a solution of metal ion $(0.0025 \mathrm{M}, 1 \mathrm{~mL})$ and reagent $(0.01 \mathrm{M}, 6 \mathrm{~mL})$ was taken in a beaker and the $\mathrm{pH}$ was adjusted to 5.0 with buffer and the volume was made up to $25 \mathrm{~mL}$ with DMF. The absorbance was measured in the range 300-800 nm.

On plotting the absorbance spectra it was observed that the absorbance of the complex increased continuously towards a shorter wavelength. The spectra showed a shoulder band at $450 \mathrm{~nm}$ and hence all the measurements were done at $450 \mathrm{~nm}$.

The V(V)-HnPBAO complex was found to be insoluble in chloroform, dioxane, ethyl acetate etc but it was soluble in DMF. For spectrophotometric studies varying amounts of $\mathrm{V}(\mathrm{V})$ solution was taken and $\mathrm{pH}$ was adjusted to 5.0 with acetic acid - sodium acetate buffer and HnPBAO solution was added and made up to $25 \mathrm{~mL}$ using DMF and the absorbance measured against reagent blank.

\section{Validity of Beer's law}

The V(V)-HnPBAO complex in DMF obeys Beer's law up to $20.38 \mathrm{ppm}$. Beyond this concentration the absorbance plot showed deviation from linearity (Figure 1). Standard graph thus obtained may be used for the determination of vanadium in an unknown solution using HnPBAO. Molar absorptivity calculated from Beer's law plot was found to be $10.22 \times 10^{2} \mathrm{~L} / \mathrm{mol} / \mathrm{cm}$ for $\left.\mathrm{V}(\mathrm{V})\right)-\mathrm{HnPBAO}$ at $450 \mathrm{~nm}$ and Sandell's sensitivity was calculated and found to be $0.049 \mu \mathrm{g} / \mathrm{cm}^{2}$ of $\mathrm{V}(\mathrm{V})$ at $450 \mathrm{~nm}$.

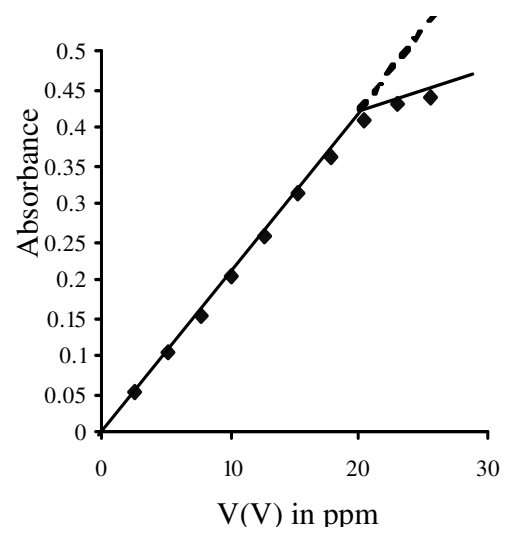

Figure 1. Beer's Law Plot for V(V)- HnPBAO Complex.

Plot of Job's method of continuous variation for determination of M: $\mathrm{L}$ ratio $0.001 \mathrm{M}$ $\mathrm{V}(\mathrm{V}), 0.001 \mathrm{M}$ HnPBAO, $\mathrm{pH}=5.0, \lambda=450 \mathrm{~nm}$ 


\section{Stoichiometry of complex}

The stoichiometry of V(V)-HnPBAO complex was determined by Job's method of continuous variation ${ }^{6}$ and Yoe Jone's mole ratio method ${ }^{7}$ (Figure 2 and 3) Both the methods gave the metal:ligand ratio of the complex as 1:1. This is in agreement with the stoichiometry found from gravimetry.

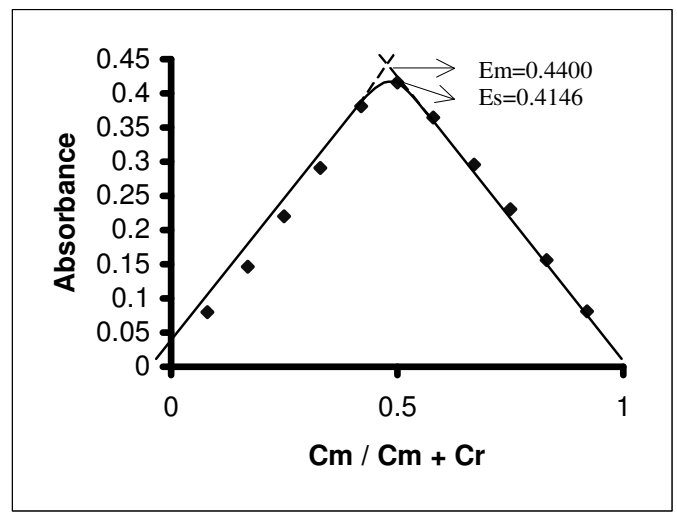

Figure 2. Job's Method for V(V)-HnPBAO Complex.

Plot of Job's method of continuous variation for determination of M:L ratio $0.001 \mathrm{M} \mathrm{V}(\mathrm{V}), 0.001 \mathrm{M} \mathrm{HnPBAO}, \mathrm{pH}=5.0, \lambda=450 \mathrm{~nm}$.

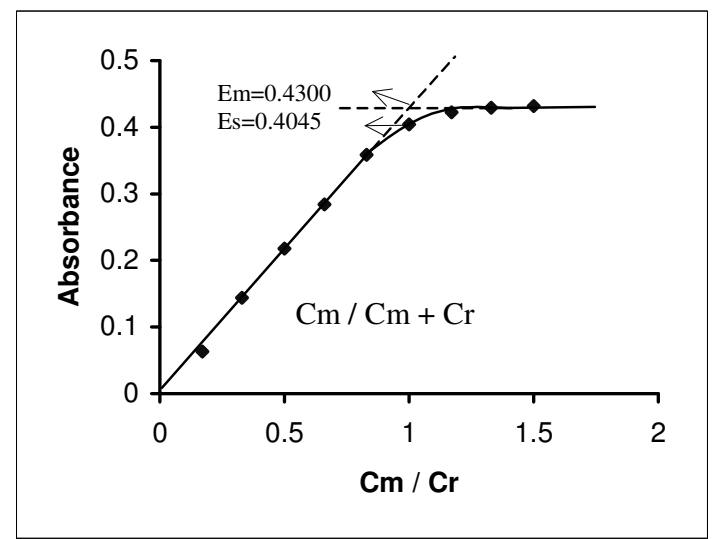

$\mathrm{Cm} / \mathrm{Cr}$

Figure 3. Mole-Ratio method for V(V)-HnPBAO Compex

Plot of Yoe and Jones method for determination of M:L ratio

$0.001 \mathrm{M} \mathrm{V}(\mathrm{V}), 0.001 \mathrm{M} \mathrm{HnPBAO}, \mathrm{pH}=5.0, \lambda=450 \mathrm{~nm}$

\section{Stability constant of the complex}

The stability constants of the complex were calculated using the formula Ks $=(1-\alpha) / 4 \alpha^{3} \mathrm{C}^{2}$ where $\alpha=(\mathrm{Em}-\mathrm{Es}) / \mathrm{Em}$.

$\mathrm{Em}=$ maximum absorbance obtained at the intersect of the two lines Es = absorbance at the stoichiometric ratio of the metal to the reagent in complex. 
The average stability constant found from two methods is $1.195 \times 10^{6}$ from Ks value. Gibb's free energy change for complex formation reaction was calculated and its value was found to be $-8.34 \mathrm{kcal} / \mathrm{mol}$ at $27{ }^{\circ} \mathrm{C}$.

\section{Determination of vanadium in ferro-vanadium alloy}

The Ferro-vanadium alloy was obtained from National Metallurgical Laboratory, Jamshedpur. It was weighed exactly $(156.70 \mathrm{mg})$ and dissolved in a mixture of concentrated nitric acid and hydrochloric acid (1:3) by heating on a sand bath. Excess nitric acid was evaporated and the solution was diluted to $100 \mathrm{~mL}$ with distilled water.

$10 \mathrm{~mL}$ aliquot was taken and $\mathrm{V}(\mathrm{V})$ was determined gravimetrically using $\mathrm{HnPBAO}$ at pH 5.0. Fe(III) was masked by adding sodium fluoride. The experiment was repeated three times. Percentage vanadium found: $51.77 \%$, Percentage vanadium reported: $52.10 \%$.

\section{Conclusion}

2-Hydroxy-4-n-propoxy-5-bromoacetophenoneoxime (HnPBAO) is a suitable reagent for spectrophotometric determination of $\mathrm{V}(\mathrm{V})$. Many cations and anions were not found to interfere.

\section{References}

1. Rao M S, Prasad N B L and Reddy KH, Indian J Chem., 2006, 45A, 1659.

2. Gandhi H C and Desai KK, Asian J Chem., 2003, 15, 549.

3. Shingadia S K and Desai K K, Oriental J Chem., 2006, 22(3)

4. Desai B D and Desai K K, Asian J Chem., 2001, 13, 334.

5. Purohit K and Desai K K, Acta Ciencia Indica, 2005, 4, 329.

6. Job P, Ann Chem., 1938, 115, 332

7. Yoe J H and Jones A L, Indian Eng Chem Anal Ed., 1944, 16, 111. 


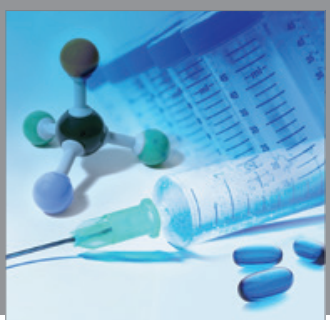

International Journal of

Medicinal Chemistry

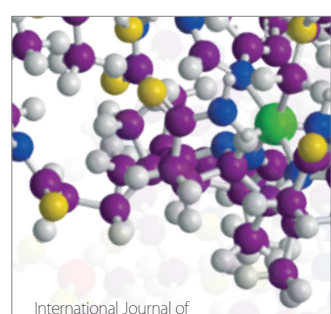

Carbohydrate Chemistry

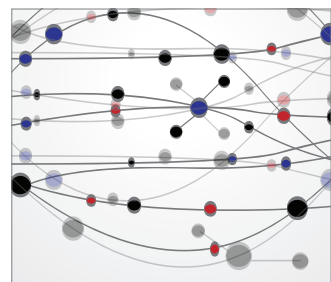

The Scientific World Journal
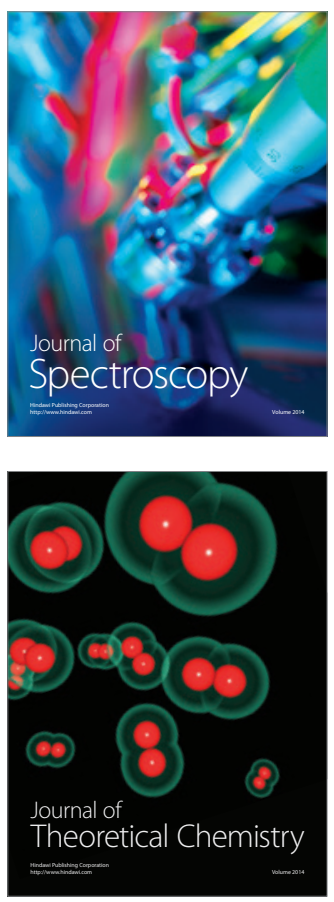
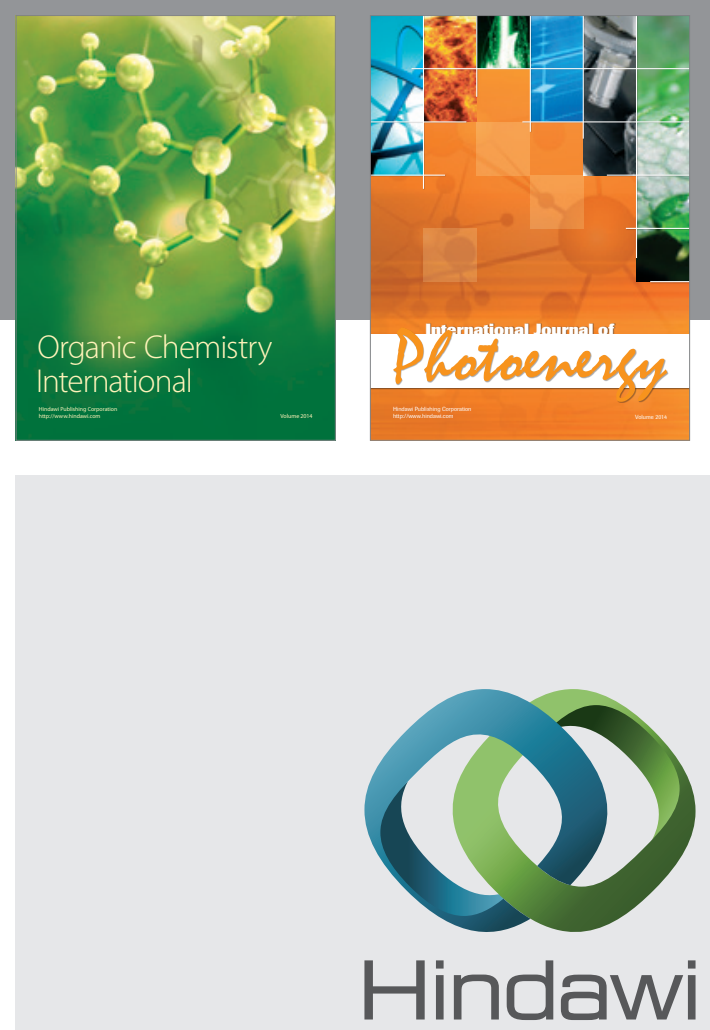

Submit your manuscripts at

http://www.hindawi.com

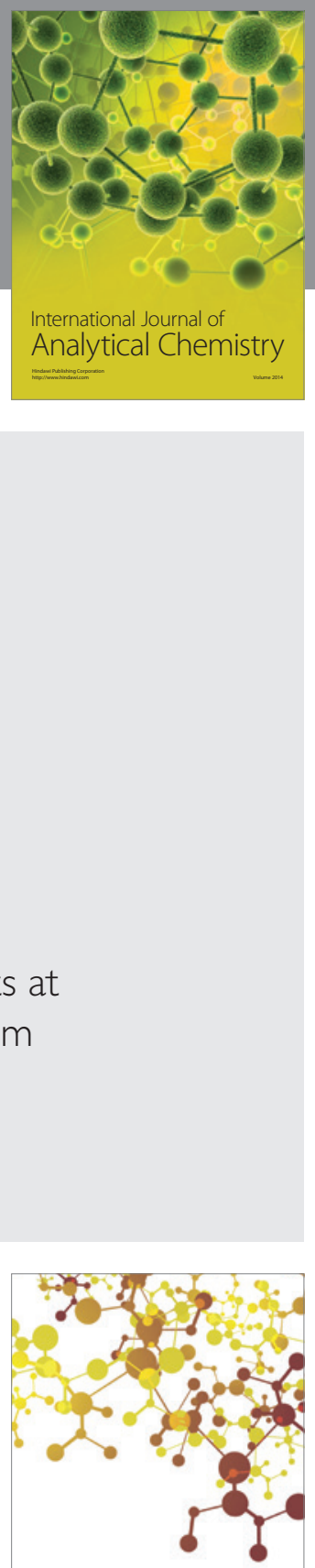

Journal of

Applied Chemistry
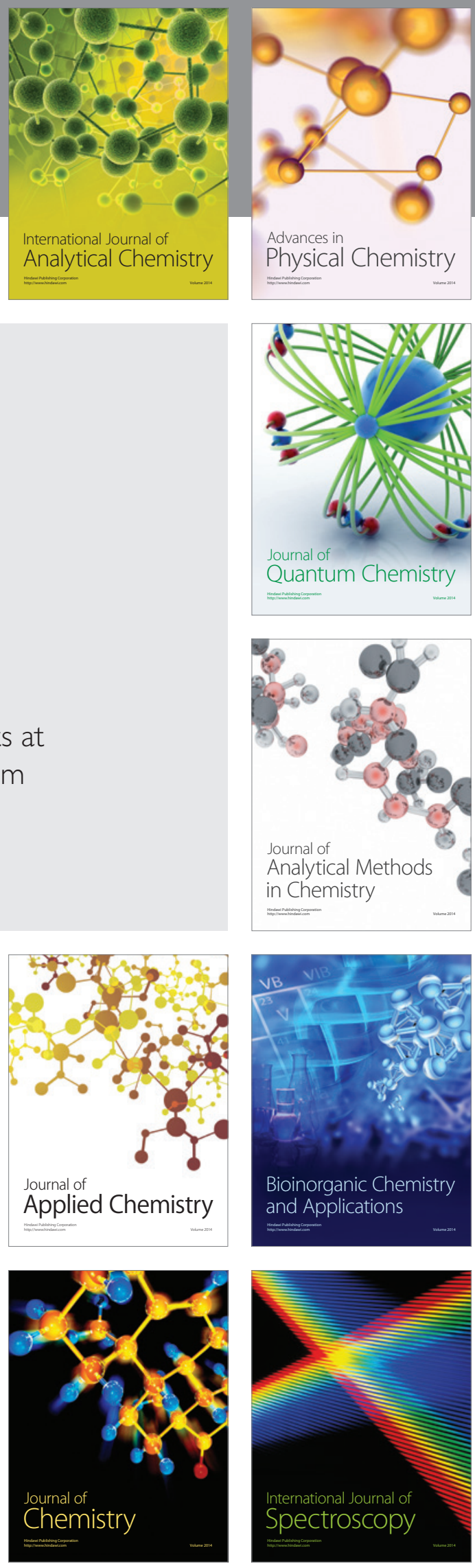